\title{
Chapter 1 \\ Responsiveness as a Key Predictor of Happiness: Mechanisms and Unanswered Questions
}

\author{
Emre Selcuk, Ayse Busra Karagobek, and Gul Gunaydin
}

\begin{abstract}
The importance of close relationships for happiness has long been recognized. This long-held interest has produced an increase in relevant empirical work investigating the links between relationships and personal well-being in the last three decades. Recent attempts at integrating this vast body of literature suggest that responsiveness - i.e., the belief that close relationship partners understand, validate, and care for us-is a core process linking close relationships to health and happiness. In the present chapter, we review the links between responsiveness and happiness, with an emphasis on studies of marital and long-term romantic relationships. The available evidence indicates that partner responsiveness improves happiness in both negative contexts (by preserving happiness in the face of stress and adversity) and positive contexts (by augmenting and prolonging happiness induced by pleasant events and supporting the pursuit of personally meaningful goals and selfactualization). We believe that future work should build on this literature by investigating intergenerational effects of partner responsiveness on offspring happiness, comparing the roles of different social network members in happiness, examining how cultural grounding of relationships modulate the responsiveness-happiness link, and identifying the different components of responsiveness critical for happiness across cultures and developmental stages.
\end{abstract}

The crucial relevance of close relationships for how happy and healthy we are "from the cradle to the grave" has long been at the center of psychological theorizing (Bowlby, 1988; Harlow, 1958; Hofer, 1984). After the mid-80s, this long-held interest was complemented with a rapidly growing body of empirical evidence on the protective (or detrimental) effects of relationships on physical and psychological

E. Selcuk $(\bowtie) \cdot$ A. B. Karagobek

Middle East Technical University, Ankara, Turkey

e-mail: semre@metu.edu.tr

G. Gunaydin

Bilkent University, Ankara, Turkey 
well-being obtained in hundreds of studies involving thousands of respondents. For instance, a recent meta-analysis combining 148 studies that involve a total of more than 300,000 adults showed that quality of social relationships is linked with a $50 \%$ increase in chances of survival (Holt-Lunstad, Smith, \& Layton, 2010). This figure rivals the effects of many oft-noted health risks including smoking, blood pressure and other cardiovascular problems, sedentary activity, air pollution, alcohol consumption, and obesity. Social relationships are consistently associated with not only physical health but also happiness. Whether with a spouse, partner, family, or friends, people see relationships as a major source of happiness across the globe (Crossley \& Langdrigde, 2005; Demir, 2015; Pflug, 2009). Indeed, in daily life, the moments that we feel the happiest usually include social interaction with another person (Kahneman, Krueger, Schkade, Schwarz, \& Stone, 2004; Killingsworth \& Gilbert, 2010). In addition to boosting positive mood in the short-term, maintaining stable relationships also promotes happiness in the long-term (e.g., Lakey, 2013; Proulx, Helms, \& Buehler, 2007; Ramsey \& Gentzler, 2015). Even temporary separations from relationship partners can bring down our mood (Diamond, Hicks, \& Otter-Henderson, 2008) and reunion is met with joy (Bowlby, 1979). Furthermore, the permanent dissolution of these bonds (through breakup or loss) leads to persistent decreases in happiness, sometimes down to such a level that returning to pre-loss levels of happiness may be difficult or take a long time (Lucas, 2007).

Although decades of research consistently documented that close relationships (or lack thereof) are tightly linked with health and happiness, a fundamental question is yet to be fully addressed-what aspects of relationships are associated with these outcomes, and through which psychological mechanisms? In this chapter, we highlight the central importance of one relationship process, perceived responsiveness, which has increasingly been linked to protective health and well-being benefits (Reis, 2012a; Selcuk \& Ong, 2013). We have recently reviewed the links between responsiveness and physical health elsewhere (Slatcher \& Selcuk, 2017), so here we focus on the role of responsiveness in happiness with an emphasis on studies about marital and long-term romantic relationships. We begin with a brief description of responsiveness, followed by a review of existing evidence on the associations between responsiveness and happiness and the mechanisms underlying these associations. We conclude with a discussion of future research directions.

\subsection{Responsiveness as an Integrating Concept in Relationship Science}

Broadly, responsiveness refers to the extent to which individuals believe their close relationship partners understand, validate, and care for them (Reis, Clark, \& Holmes, 2004). It entails the belief that relationship partners are attentive to our needs, desires, and experiences, that they appreciate and agree with our point of view, and that they are able to provide empathy, affection, and care (Maisel, Gable, \& 
Strachman, 2008). Recent theorizing by Harry Reis and colleagues (Reis, 2007; Reis et al., 2004), which has been a guiding framework for us and many others, conceptualizes responsiveness as a core process cutting across all influential developmental and social psychological theories of relationships, such as attachment theory (e.g., Bowlby, 1988), social support theory (Cutrona, 1996), and applications of interdependence theory (Drigotas, Rusbult, Wieselquist, \& Whitton, 1999). Common to all of these theories is the idea that relationships with understanding, validating, and caring partners promote personal and relationship well-being (see Reis et al. (2004) and Reis (2013) for detailed discussions of the role of responsiveness in major psychological theories). Among these theoretical perspectives, attachment theory is perhaps the one that most prominently features responsiveness as a critical feature of human bonds shaping social and psychological development across the lifespan (Bowlby, 1988). According to attachment theory, parental responsiveness in early life not only contributes to long-term happiness but also lays the foundations of how individuals form and maintain new social relationships in adulthood, including friendships and romantic bonds (Zayas, Mischel, Shoda, \& Aber, 2011). These adult relationships, in turn, continue to influence personal and relationship well-being (e.g., Simpson, Collins, Tran, \& Haydon, 2007).

Responsiveness as an interpersonal process in adulthood was first systematically formulated in the context of relationship formation and development (Reis \& Shaver, 1988). When we perceive our partners as understanding, validating, and caring, we are more likely to self-disclose and to react responsively to their disclosures. When this process is enacted reciprocally and mutually, it reinforces the development and maintenance of intimacy, and bolsters relationship satisfaction. This initial work, together with subsequent elaborations, revisions, and refinements (Reis, 2007; Reis et al., 2004; Reis \& Gable, 2015) provides the guiding theoretical framework to study the role of responsiveness in relationship and personal well-being.

Romantic bonds are the prototypical adult social relationships where the interplay between self-disclosure and responsiveness and the resulting increase in intimacy are commonly observed. In addition, stable romantic bonds allow researchers to study couples for a long period of time (sometimes spanning over several years) when many of the strong effects of responsiveness can be observed. Therefore, the majority of what we know about the links between responsiveness and happiness is based on research with romantic couples. As a result, our review of the existing evidence mostly focuses on long-term pair bonds. This does not mean that responsiveness is irrelevant to other types of relationships (e.g., parental, friendships) or developmental periods (e.g., infancy and childhood). On the contrary, responsiveness can be thought of as an organizing construct to study all close social bonds across different developmental stages. We believe that existing findings with romantic couples can provide a strong foundation on which an understanding of the lifespan effects of responsiveness can be built. Therefore, after reviewing evidence on the links between partner responsiveness and happiness, we revisit these important issues at the end of the chapter. 


\subsection{Partner Responsiveness and Happiness}

When asked what happiness is, individuals nominate different indicators, including achieving pleasure and avoiding pain, having a meaningful and purposeful life, and maintaining satisfying relationships (Furnham \& Cheng, 2000; Lu, 2001; Pflug, 2009). Extensive work with diverse samples of adults from different age groups and cultures provides strong empirical support to these lay theories of happiness by demonstrating that hedonia (life satisfaction and positive affect; Pavot \& Diener, 2013), eudaimonia (fulfilling one's potential, finding meaning in life, and meeting lifespan developmental challenges; Ryff, 2013), and relationship satisfaction generally form empirically distinct (albeit correlated) higher-order indicators of wellbeing (e.g., Gallagher, Lopez, \& Preacher, 2009; Lindfors, Berntsson, \& Lundberg, 2006; van Dierendonck, 2004).

Prior work has linked partner responsiveness with all three forms of happiness. First, partner responsiveness predicts better relationship well-being in daily life. On days when individuals perceive their partner as more responsive, they also feel greater intimacy in their relationship (Otto, Laurenceau, Siegel, \& Belcher, 2015). These repeated responsive interactions with a partner in daily life culminate in an increase in relationship satisfaction over time (Drigotas et al., 1999).

Partner responsiveness is also a strong predictor of the hedonic aspect of happiness in daily life, typically operationalized as life satisfaction and/or positive affect (Drigotas, 2002; Otto et al., 2015). Experimental evidence also demonstrates that individuals who were led to believe that their partner was responsive (vs. unresponsive) to them during a challenging laboratory task experienced greater positive affect (Feeney, 2004), providing evidence for the causal link between partner responsiveness and hedonic well-being.

The link between partner responsiveness and eudaimonic well-being has received relatively less empirical attention, at least until recently. This is probably because the role of responsiveness has traditionally been conceptualized as preserving personal and relationship happiness in times of stress. Increasing appreciation of the role of partner responsiveness in positive contexts (as we elaborate in more detail below) has led to studies investigating its consequences for eudaimonic well-being. For instance, experimentally enhancing close others' responsiveness reduces defensive reactions to failure (attributing failure to external sources) (Caprariello \& Reis, 2011). Moreover, discussing personal goals with a responsive partner is associated with increased confidence in goal attainment (Feeney, 2004). These processes are expected to promote self-acceptance and personal growth, and to contribute to longterm increases in eudaimonic well-being. In a recent investigation of this issue during middle and late adulthood (Selcuk, Gunaydin, Ong, \& Almeida, 2016), we found that partner responsiveness predicted increases in eudaimonic well-being (measured by feelings of autonomy, environmental mastery, self-acceptance, personal growth, and purpose in life) and hedonic well-being (measured by positive affect, reverse-scored negative affect, and life satisfaction) a decade later. Moreover, the benefits of partner responsiveness for eudaimonic (but not hedonic) well-being 
held even after additionally controlling for initial levels of well-being, responsiveness of other network members including family and friends, and demographic (age and gender) and personality factors (extraversion and neuroticism) known to affect happiness. These findings indicate that the long-term association of partner responsiveness with change in eudaimonic well-being is unique and not explained by the well-known demographic and personality predictors of happiness as well as responsiveness of other social network members.

In sum, prior work documented the relevance of partner responsiveness for different aspects of happiness including hedonia, eudaimonia, and relationship wellbeing. The theoretical causal link has been supported in experimental studies manipulating responsiveness or in naturalistic studies modeling change in happiness (i.e., predicting happiness at a later time point by controlling initial happiness). Finally, partner responsiveness has a discriminant role in predicting happiness, since its effects hold even after adjusting for demographic, personality, or other psychosocial factors predicting happiness.

\subsection{Mechanisms Underlying the Effect of Partner Responsiveness on Happiness}

What are the processes by which partner responsiveness is linked with happiness? Traditionally, the role of partner responsiveness was conceptualized as one of protection in times of stress. Accordingly, partner responsiveness was thought to preserve happiness by buffering emotional reactivity as individuals go through stressful life experiences. However, recent theorizing argues that the role of responsiveness is not only limited to preserving baseline happiness in stressful contexts but also extends to promoting happiness in positive contexts (Feeney \& Collins, 2014). Most of the psychological mechanisms underlying the impact of responsiveness on happiness in bad or good times can be traced back to Bowlby's (1988) attachment theory, which ascribes a central role to responsiveness in human development.

\subsection{Buffering Stress Reactivity in Negative Contexts}

According to attachment theory, a core function of responsiveness is buffering reactivity to stressful events. In early life, parents or primary caregivers who are available and responsive to their infant's needs help regulate the infant's stress reactivity. Through repeated interactions with attachment figures who are consistently responsive, infants develop a sense of "felt security" (Sroufe \& Waters, 1977), which in turn promotes adaptive stress regulation as indicated by decreases in biological markers of reactivity to stress and novelty such as cortisol levels (Gunnar, Brodersen, Krueger, \& Rigatuso, 1996) or right frontal cortical activity (Hane \& Fox, 2006). 
Recent evidence suggests that the influence of parental responsiveness on stress regulation capacity extends even to adulthood (Mallers, Charles, Neupert, \& Almeida, 2010). In adulthood, however, parents are gradually replaced by long-term marital or romantic partners as primary attachment figures that help regulate stress reactivity and anxiety (Selcuk, Stanton, Slatcher, \& Ong, 2017; Selcuk, Zayas, \& Hazan, 2010). Indeed, numerous studies demonstrate that warm, supportive interactions with romantic partners reduce reactivity to acute laboratory stressors (such as giving a public speech, receiving a mildly painful stimulus, disclosing a recent worry) as reflected by smaller elevations in self-reported and observer-rated stress and negative affect (Collins \& Feeney, 2000; Simpson, Rholes, \& Nelligan, 1992), endocrine responses (cortisol; Ditzen et al., 2007), and cardiovascular reactivity (blood pressure and heart rate; Grewen, Anderson, Girdler, \& Light, 2003) as well as reduced activation of neural systems regulating threat responses (Coan, Schaefer, \& Davidson, 2006).

At the neurobiological level, the effects of partner responsiveness are thought to be mediated by oxytocin and endogenous opioid systems. Repeated responsive interactions with romantic partners elevate oxytocin and opioid neurotransmission (Depue \& Morrone-Strupinsky, 2005; Uvnas-Moberg, 1998), both of which lead to potentially persistent long-term down-regulations in biological stress response systems such as the hypothalamic-pituitary-adrenal (HPA) axis. For instance, one study (Slatcher, Selcuk, \& Ong, 2015) observed that partner responsiveness is prospectively linked with steeper ("healthier") declines in daily cortisol (the hormonal output of the HPA axis) 10 years later. The stress buffering effects of relationships are so potent that upon repeated interactions with responsive partners, merely thinking about them or looking at their photograph may instill the psychobiological processes originally activated by the partners' physical presence (Zayas, Günaydin, \& Shoda, 2015) and help regulate reactivity to stress and pain (Eisenberger et al., 2011; Selcuk, Zayas, Günaydın, Hazan, \& Kross, 2012).

These reductions in neural, physiological, and subjective reactivity to stressful events that come with maintaining a relationship with a responsive partner help preserve happiness even in the face of adversity. For instance, in women coping with breast cancer and their romantic partners, daily partner responsiveness positively predicted daily relationship well-being and positive affect (Otto et al., 2015). Similarly, in women coping with lupus (a chronic autoimmune disease that affects connective tissue and increases the risk for organ damage) and their spouses, partner responsiveness predicted greater marital satisfaction and lower depression for both husbands and wives (Fekete, Stephens, Mickelson, \& Druley, 2007). Similar decreases in depression linked with high partner responsiveness were observed also in individuals who were recovering from knee surgery (Khan et al., 2009). Taken together, the evidence from studies of couples going through health-related stressors converge with the evidence from laboratory studies on the stress buffering role of partner responsiveness.

Lower stress reactivity also mediates the link between partner responsiveness and eudaimonic well-being. A responsive partner who has your back if things go wrong increases confidence in autonomously and purposefully pursuing personal 
goals and exploring the world even in the face of adversity (Mikulincer \& Shaver, 2007). To the extent that individuals show lower reactivity to daily stressors, they are more likely to continue working toward daily life responsibilities and goals, learning new information and engaging in new experiences, and growing as a person in an uninterrupted manner. In our 10-year longitudinal analyses (Selcuk et al., 2016), we also examined whether the association between partner responsiveness and increase in eudaimonic well-being was mediated by lower stress reactivity in daily life. A subset of respondents participated in an 8-day diary study where they completed measures of daily stressful events (e.g., having an argument, encountering a problem at work, something bad happening to a close other, perceived discrimination) and negative affect, allowing us to capture stress reactivity in daily life. Specifically, we computed a within-person slope for each respondent corresponding to change in negative affect from a day with no stressors to a stressful day. Partner responsiveness predicted lower reactivity to daily life stressors, which, in turn, predicted increases in eudaimonic well-being a decade later. Lower stress reactivity accounted for $11 \%$ of the association between partner responsiveness and increase in eudaimonic well-being a decade later, providing further evidence that reducing reactivity to stressful events is one of the key mechanisms by which partner responsiveness contributes to happiness.

\subsection{Promoting Happiness in Positive Contexts}

Increasing evidence indicates that the role of partner responsiveness in happiness is not limited to preserving baseline happiness in the face of adversity. Partner responsiveness is also a resource which helps individuals thrive in positive contexts (Feeney \& Collins, 2014). Here we illustrate the happiness-promoting role of responsiveness in two domains: reacting to a partner's disclosures of positive experiences and enabling a partner to achieve their ideal self.

When something good happens in our life (e.g., getting a promotion), most of us itch to share it with our partners. Langston (1994) referred to this process of conveying positive personal events to others as capitalization. By telling others, people expect them to share the excitement and respond positively. Does sharing good news with significant others augment the happiness induced by the event? An impressive program of research by Harry Reis, Shelly Gable and their colleagues (see Gable \& Reis, 2010 for a review) reveals that the answer is yes, but mostly when significant others react responsively to capitalization attempts. Sharing positive events enhances and prolongs the happiness induced by the event to the extent that individuals feel that their partner understands (e.g., listens attentively what they share, gathers information about the event), validates (e.g., expresses appreciation and agreement), and cares for them (e.g., shows love and affection, expresses empathy) (Maisel et al., 2008). In daily life, partner responsiveness to capitalization attempts predicts diverse indicators of happiness including relationship satisfaction 
(Gable, Reis, Impett, \& Asher, 2004) and hedonic well-being (Gable, Gosnell, Maisel, \& Strachman, 2012; Monfort et al., 2014). Importantly, these effects hold even when positivity of the event itself is partialled out, indicating that the role of partner responsiveness goes above and beyond individual differences in positivity of shared events. Although more direct evidence on its effects on eudaimonic wellbeing is needed, responsiveness to capitalization attempts has also been linked to a more open, exploratory mindset (Gable \& Reis, 2010), which is likely to lead to behaviors and experiences that build eudaimonic well-being.

Indeed, an open-minded and exploratory view of the world, confidence in achieving personal goals, and persistence in goal pursuit even when things do not go as planned are the building blocks of achieving one's ideal self and experiencing eudaimonic well-being. Accomplishing these things in life is easier said than done, but attachment theory argues that these accomplishments are less difficult for individuals who have a partner serving as a "secure base" from which they can explore the world (Bowlby, 1988). And responsiveness is the heart of the "secure base" process (Cutrona \& Russell, 2017). The mediating role of partner responsiveness in helping individuals achieve their ideal self is elegantly demonstrated in Rusbult and colleagues' research program on the Michelangelo phenomenon. Although Rusbult herself approached the issue from an interdependence theory perspective, partners' roles in supporting each other's ideal self in Rusbult's model resemble the attachment theoretical role of romantic partners in supporting each other's exploratory behavior. The Michelangelo phenomenon refers to the process by which partners "sculpt" each other into their respective ideal selves. This process entails the belief that the partner can achieve their ideal self (referred to as perceptual affirmation). It also requires behaving in ways that elicit ideal-congruent qualities in the self (referred to as behavioral affirmation). In several studies, Rusbult and colleagues demonstrated that partner perceptual or behavioral affirmation prospectively led to movement toward the ideal self (Drigotas et al., 1999; Kumashiro, Rusbult, Wolf, \& Estrada, 2006). Movement toward the ideal self, in turn, promoted both relational and personal happiness (Drigotas, 2002; Drigotas et al., 1999).

Overall, accumulating evidence indicates that partner responsiveness confers benefits for well-being not only in negative contexts but also in positive contexts (Cutrona \& Russell, 2017). Growing converging evidence from experimental, longitudinal, and daily diary studies indicates that partner responsiveness cultivates happiness derived from pleasant experiences. Importantly, the increase in the level and duration of happiness persists even after controlling for the initial positivity of the experience. Moreover, partner responsiveness helps individuals work toward purposeful and meaningful goals and grow as a person.

One issue is whether the documented benefits of partner responsiveness for hedonic and eudaimonic well-being as well as relationship satisfaction differ across women and men. Attachment theory does not make any explicit predictions about the potential moderating role of gender-that is, partner responsiveness is expected to benefit both men and women. However, other theoretical perspectives argue that the benefits may be larger for women than for men. For instance, the tend-andbefriend model (Taylor, 2002) argues that because women were historically more 
involved in child care, turning to close others in times of threat and adversity was more critical for them than it was for men. This tendency worked to ensure the joint safety and protection of the women themselves as well as their offspring. As a result, women may have developed greater sensitivity to the quality and maintenance of their relationships. The idea that this tendency translates to a reliable increase in the importance of partner responsiveness for happiness and well-being, however, has received mixed empirical support. Most studies detected no gender difference in the association between partner responsiveness and happiness (e.g., Collins \& Feeney, 2000; Drigotas, 2002; Gable et al., 2012; Grewen et al., 2003; Mallers et al., 2010). However, in the few cases when there was a significant gender difference, the benefits were greater for women as compared to men (e.g., Selcuk et al., 2012), as the tend-and-befriend model predicts (see also Sapphire-Bentler \& Taylor, 2013).

\subsection{Unanswered Questions and Directions for Future Research}

Despite advances in our understanding of the ways by which partner responsiveness enhances happiness, there are still questions remaining to be addressed in future research. First, although most of the extant work on partner responsiveness (including our own) has been heavily influenced by the developmental attachment theory, research on partner responsiveness in adulthood and on caregiver responsiveness in early life have remained relatively disparate. The integration of these two research lines may help us understand whether responsiveness leads to intergenerational effects on happiness. Are individuals with responsive partners also more likely to be responsive caregivers, which in turn leads their children to be happier and more responsive in their close relationships (including romantic and parental bonds), which increases the chances that their offspring would evidence greater responsiveness and happiness, and so on? Initial evidence suggests that such intergenerational links may be likely. For example, mothers who are avoidantly attached to their husbands (and hence, likely to perceive them as less responsive) are also less likely to be available and responsive to the needs of their offspring both in early childhood (Selcuk et al., 2010) and in adolescence (Stanton et al., 2017). Notably, maternal responsiveness, in turn, predicts healthier biological regulation of stress responses in adolescence (Stanton et al., 2017), showing that partner responsiveness may affect not only one's own well-being but also that of one's offspring. Whether such intergenerational effects also exist for offspring happiness is an important question for future research.

Another important question concerns the generalizability of the link between partner responsiveness and happiness across cultures. The present volume is comprised of excellent examples on how culture shapes the links between close relationships and happiness. Most of the work we reviewed here was conducted with North American samples. Does what we know about the associations between partner 
responsiveness and the various indicators of happiness generalize to other cultures? Although forming and maintaining attachments is a normative aspect of human development and has been observed across virtually all parts of the world, there are several reasons to expect that the magnitude of the association between partner responsiveness and well-being may differ across cultures. For one, relationship formation and development processes differ across the Western and non-Western worlds. The Western perspective on romantic relationships emphasizes personal choice and voluntary effort as the basis of relationship formation. Individuals are thought to "select" a mate who possess desired physical and psychological characteristics-with responsiveness being one of them (Goodwin, 1999). Mutual engagement in self-disclosure and reacting responsively to these self-disclosures (whether negative or positive as we have reviewed) is seen as the catalyst of intimacy (Reis \& Shaver, 1988). Furthermore, the couple is seen as a relatively separate unit from the partners' family (as reflected both physically in separate living arrangements and psychologically in preference of partners to view each other as the primary source and recipient of support; e.g., Zeifman \& Hazan, 2008). In contrast, in cultures where the self is not seen as an agentic force shaping social reality but rather as embedded in a network of (oftentimes inescapable) social relationships (e.g., East Asia or West Africa; Adams, Anderson, \& Adonu, 2004), pair bonds are perceived as a product of incontrollable situational factors such as fate or, as in the case of arranged marriages, the preferences of kin (as opposed to preferences of prospective spouses). Even when a marriage is not arranged in the strictest sense, the opinions of family members may be weighted more heavily in marriage initiation in the nonWestern world. To the extent that beliefs in relationship formation do not reflect personal choice and voluntary effort, bases of mate preferences (e.g., physical attractiveness, partner responsiveness) should be less predictive of personal wellbeing (see also Anderson, Adams, \& Plaut, 2008). Moreover, self-disclosure and responsiveness to these disclosures may not be the defining characteristic of the relationship, but other factors such as kin keeping may take precedence, making partner responsiveness a weaker predictor of both relational and personal wellbeing. Finally, marriage may be seen as a way to further strengthen one or both partners' ties with their extended families, suggesting the possibility that partners may not necessarily become the preferred source and recipient of support, which would again lead to a weaker association between partner responsiveness and well-being.

Based on this reasoning, we have recently compared the link between partner responsiveness and well-being across the United States (where the self is seen more as an independent entity, relationships are seen as a product of the voluntary actions and choices of the agentic self, and self-disclosure is a critical factor mediating relationship development) and Japan (where the self is seen more as an interdependent entity embedded in social relationships and a less powerful agent in determining relationship formation or dissolution, and self-disclosure is a less defining characteristic of social relationships). Indeed, although partner responsiveness predicted hedonic and eudaimonic well-being with small-to-medium effect sizes (Cohen, 1988) in both cultures, the slopes were smaller in Japan than in the United 
States (Tasfiliz, Selcuk, Gunaydin, Slatcher, Corriero, \& Ong, 2018). Overall, these findings support the theoretical argument that partner responsiveness is more strongly linked with happiness in contexts where relationship formation is based on personal volition and effort, self-disclosure is a defining feature of relationships, and high residential mobility is likely to limit the functions of other existing social ties. A subsequent study in Turkey (Tasfiliz, Sagel, \& Selcuk, 2016), where independent values have been steadily increasing over the last two decades while interdependent values are retained, also revealed a positive association between partner responsiveness and well-being, with an effect size similar to that observed in the United States.

In addition to influencing the strength of the association between partner responsiveness and happiness, the cultural construction of relationships may also shape how responsiveness of different relationship partners (e.g., spouses, adult children, parents, close friends) affects happiness. Majority of researchers studying functions of responsiveness in adulthood, including ourselves, opt to focus mainly on partner responsiveness. There are both practical and theoretical reasons for this choice. On the practical side, as we have mentioned earlier, the pair bond (and its institutional form, marriage) allows researchers to study couples over a long period of time, during which the effects of relationships on health and happiness are realized. On the theoretical side, marriage (or long-term cohabitation) is thought to be the primary attachment relationship in adulthood (Bowlby, 1979) shaping biological, psychological, and social functioning. This theoretical contention received strong empirical support in Western samples, with adults consistently preferring their spouse or long-term romantic partner as the primary attachment figure (Doherty \& Feeney, 2004; Fraley \& Davis, 1997; Markiewicz, Lawford, Doyle, \& Haggart, 2006; Zeifman \& Hazan, 2008). As such, partner responsiveness is thought to confer benefits above and beyond responsiveness of other social network members, including family and close friends. This is not to say that responsiveness of other social network members is unimportant. For instance, work on capitalization finds that other social network members' (e.g., friends, parents) responsiveness to capitalization attempts also improves personal well-being (Demir \& Davidson, 2013; Demir, Doğan, \& Procsal, 2013; Demir, Haynes, \& Potts, 2017; Gable et al., 2004; Gable \& Reis, 2010, Gore, Cross, \& Morris, 2006). However, partner responsiveness is thought to have a particularly potent effect. Indeed, although researchers have called for further empirical studies looking at the independent roles of different relationship partners (Robles, Slatcher, Trombeloo, \& Mcginn, 2014), available evidence mainly from North American samples indicates that partner responsiveness may have a unique effect on health and happiness that is not accounted for or replaced by responsiveness of other social network members (e.g., Brooks et al. 2015; Selcuk et al., 2016; Vormbrock, 1993). These findings suggest that different social ties (marital, kinships, or friendships) are likely to have independent, additive associations with happiness.

But is the status of romantic partners as preferred attachment figures generalizable across cultures? In cultures where individuals are already embedded in close interdependent ties, transferring all attachment functions to the partner or spouse 
may take longer than it does in Western cultures. Moreover, partners may have lower expectations for responsiveness if they already satisfy this need using other existing close relationships_-for example, with parents, siblings, or close friends. Although direct evidence for this prediction is yet to be obtained, findings across different cultures indirectly speak to the possibility of its accuracy. First, studies show that individuals do not always see their romantic partners as the primary source of social support in East Asian cultures (Goodwin, 1999; Li \& Cheng, 2015). Moreover, in both East Asian and West African cultures romantic partners are not the primary target for support provision when compared with parents (Salter \& Adams, 2012; Wu, Cross, Wu, Cho, \& Tey, 2016). In line with these findings, Turkish wives (vs. husbands) in arranged marriages perceived lower levels of responsiveness from their spouse, possibly due to traditional gender roles ascribing a greater expectation of being responsive to wives as compared to husbands (Imamoğlu \& Selcuk, 2018). In such cases, interactions with other social network members as preferred sources of responsiveness may increase. Supporting this argument, a study with retired Turkish couples found that wives, when compared to their husbands, reported more frequent interactions with their close network of children and neighbors (Imamoğlu, Küller, Imamoğlu, \& Küller, 1993). Given these findings, future work should investigate how the effects of different social network members on happiness compare within and across cultures.

The relative importance of different social network members may change across not only cultural contexts but also developmental periods. Most of the studies we reviewed here were conducted with adults in established long-term relationships. Whether these findings would generalize to early-stage romantic relationships in emerging and young adulthood during when close friends or family are still major sources of support is an important future research direction. We speculate that although partner responsiveness would predict intimacy and satisfaction in earlystage relationships during when an attachment bond is being forged (Zeifman \& Hazan, 1997), other close relationships may remain the more critical determinants of well-being. Individual differences in motivations for forming romantic relationships (e.g., preference for remaining single or delaying committed romantic relationships; De Paulo, DePaulo, 2011; Shulman \& Connolly, 2013) may also affect the likelihood with which responsiveness of friends and family serve as predictors of happiness during emerging and young adulthood.

Finally, features of responsiveness that are relevant for happiness may differ across cultural contexts. For instance, in cultures where individuals see themselves embedded in a broad network of strong kin ties, would responsiveness to kin keeping obligations (vs. responsiveness to self-disclosures) be more strongly related with happiness? This is not a remote possibility given the prevalence of experiencing close relationships based on obligations (e.g., providing instrumental support) in non-Western settings (Adams \& Plaut, 2003).

The crucial effect of social relationships on the individual is evident as an issue of interest even in the earliest texts and teachings of civilizations across the globe (Reis, 2012b). Compared with this long-held interest, empirical work addressing how close relationships affect happiness has been recent, most notably accumulating 
in the last three decades. A growing literature indicates that partner responsiveness is a central, organizing construct linking relationships to happiness. Studies with long-term marital or romantic relationships reveal that partner responsiveness helps preserve happiness in negative contexts by alleviating affective reactivity to stressful experiences and promote happiness in positive contexts by augmenting and prolonging happiness induced by pleasant experiences and by facilitating pursuit of personally meaningful goals and self-actualization. Building on this body of knowledge, the literature will benefit from future work investigating the implications of partner responsiveness for offspring happiness, examining how cultural grounding of relationships modulate the responsiveness-happiness link, and comparing the relative roles of different social network members and different components of responsiveness across cultural contexts and developmental stages. Addressing these issues will help us gain a deeper understanding of how responsiveness shapes personal well-being.

\section{References}

Adams, G., Anderson, S. L., \& Adonu, J. K. (2004). The cultural grounding of closeness and intimacy. In D. J. Mashek \& A. Aron (Eds.), The handbook of closeness and intimacy (pp. 321339). Mahwah, NJ: Lawrence Erlbaum Associates.

Adams, G., \& Plaut, V. C. (2003). The cultural grounding of personal relationship: Friendship in North American and West African worlds. Personal Relationships, 10, 333-347. https://doi. org/10.1111/1475-6811.00053

Anderson, S. L., Adams, G., \& Plaut, V. C. (2008). The cultural grounding of personal relationship: The importance of attractiveness in everyday life. Journal of Personality and Social Psychology, 95, 352-368. https://doi.org/10.1037/0022-3514.95.2.352

Bowlby, J. (1979). The making and breaking of affectional bonds. London: Tavistock.

Bowlby, J. (1988). A secure base: Clinical applications of attachment theory. London: Routledge.

Brooks, K. P., Gruenewald, T., Karlamanga, A., Hu, P., Koretz, B., \& Seeman, T. E. (2015). Social relationships and allostatic load in the MIDUS study. Health Psychology, 33, 1373-1381. https://doi.org/10.1037/a0034528

Caprariello, P. A., \& Reis, H. T. (2011). Perceived partner responsiveness minimizes defensive reactions to failure. Social Psychological and Personality Science, 2, 365-372. https://doi. org/10.1177/1948550610391914

Coan, J. A., Schaefer, H. S., \& Davidson, R. J. (2006). Lending a hand: Social regulation of the neural response to threat. Psychological Science, 17, 1032-1039. https://doi. org/10.1111/j.1467-9280.2006.01832.x

Cohen, J. (1988). Statistical power analysis for the behavioral sciences. Hillsdale, NJ: Lawrence Earlbaum Associates.

Collins, N. L., \& Feeney, B. C. (2000). A safe haven: An attachment theory perspective on support seeking and caregiving in intimate relationships. Journal of Personality and Social Psychology, 78, 1053-1073. https://doi.org/10.1037/0022-3514.78.6.1053

Crossley, A., \& Langdrigde, D. (2005). Perceived sources of happiness: A network analysis. Journal of Happiness Studies, 6, 107-135. https://doi.org/10.1007/s10902-005-1755-z

Cutrona, C. E. (1996). Social support in couples: Marriage as a resource in times of stress. Thousand Oaks, CA: Sage Publications.

Cutrona, C. E., \& Russell, D. W. (2017). Autonomy promotion, responsiveness, and emotion regulation promote effective social support in times of stress. Current Opinion in Psychology, 13, 126-130. https://doi.org/10.1016/j.copsyc.2016.07.002 
Demir, M. (2015). Friendship and happiness: Across the life-span and cultures. Dordrecht, The Netherland: Springer.

Demir, M., \& Davidson, I. (2013). Toward a better understanding of the relationship between friendship and happiness: Perceived responses to capitalization attempts, feelings of mattering, and satisfaction of basic psychological needs in same-sex best friendships as predictors of happiness. Journal of Happiness Studies, 14, 525-550. https://doi.org/10.1007/s10902-012-9341-7

Demir, M., Doğan, A., \& Procsal, D. A. (2013). I am so happy 'cause my friend is happy for me: Capitalization, friendship, and happiness among U.S. and Turkish college students. Journal of Social Psychology, 153, 250-255. https://doi.org/10.1007/s10902-006-9012-7

Demir, M., Haynes, A., \& Potts, S. (2017). My friends are my estate: Friendship experiences mediate the relationship between perceived responses to capitalization attempts and happiness. Journal of Happiness Studies, 18(4), 1161-1190.

DePaulo, B. (2011). Singlism: What it is, why it matters, and how to stop it. Charleston, NC: DoubleDoor Books.

Depue, R. A., \& Morrone-Strupinsky, J. V. (2005). A neurobehavioral model of affiliative bonding: Implications for conceptualizing a human trait of affiliation. The Behavioral and Brain Sciences, 28, 313-395. https://doi.org/10.1017/S0140525X05000063

Diamond, L. M., Hicks, A. M., \& Otter-Henderson, K. D. (2008). Every time you go away: Changes in affect, behavior, and physiology associated with travel-related separations from romantic partners. Journal of Personality and Social Psychology, 95, 385-403. https://doi. org/10.1037/0022-3514.95.2.385

Ditzen, B., Neumann, I. D., Bodenmann, G., von Dawans, B., Turner, R. A., Ehlert, U., \& Heinrichs, M. (2007). Effects of different kinds of couple interaction on cortisol and heart rate responses to stress in women. Psychoneuroendocrinology, 32, 565-574. https://doi. org/10.1016/j.psyneuen.2007.03.011

Doherty, N. A., \& Feeney, J. A. (2004). The composition of attachment networks throughout the adult years. Personal Relationships, 11, 469-488. https://doi.org/10.1111/j.1475-6811.2004.00093.x

Drigotas, S. M. (2002). The Michelangelo phenomenon and personal Well-being. Journal of Personality, 70, 59-77. https://doi.org/10.1111/1467-6494.00178

Drigotas, S. M., Rusbult, C. E., Wieselquist, J., \& Whitton, S. W. (1999). Close partner as sculptor of the ideal self: Behavioral affirmation and the Michelangelo phenomenon. Journal of Personality and Social Psychology, 77, 293-323. https://doi.org/10.1037/0022-3514.77.2.293

Eisenberger, N. I., Master, S. L., Inagaki, T. I., Taylor, S. E., Shirinyan, D., Lieberman, M. D., \& Naliboff, B. (2011). Attachment figures activate a safety signal-related neural region and reduce pain experience. Proceedings of the National Academy of Sciences, 1081, 1172111726. https://doi.org/10.1073/pnas.1108239108

Feeney, B. C. (2004). A secure base: Responsive support of goal strivings and exploration in adult intimate relationships. Journal of Personality and Social Psychology, 87, 631-648. https://doi. org/10.1037/0022-3514.87.5.631

Feeney, B. C., \& Collins, N. L. (2014). A new look at social support: A theoretical perspective on thriving through relationships. Personality and Social Psychology Review, 19, 113-147. https:// doi.org/10.1177/1088868314544222

Fekete, E. M., Stephens, M. A. P., Mickelson, K. D., \& Druley, J. A. (2007). Couples’ support provision during illness: The role of perceived emotional responsiveness. Families, Systems, \& Health, 25, 204-217. https://doi.org/10.1037/1091-7527.25.2.204

Fraley, R. C., \& Davis, K. E. (1997). Attachment formation and transfer in young adults' close friendships and romantic relationships. Personal Relationships, 4, 131-144. https://doi. org/10.1111/j.1475-6811.1997.tb00135.x

Furnham, A., \& Cheng, H. (2000). Perceived parental behaviour, self-esteem and happiness. Social Psychiatry and Psychiatric Epidemiology, 35, 463-470. https://doi.org/10.1007/ s001270050265

Gable, S. L., Gosnell, C. L., Maisel, N. C., \& Strachman, A. (2012). Safely testing the alarm: Close others' responses to personal positive events. Journal of Personality and Social Psychology, 103, 963-981. https://doi.org/10.1037/a0029488 
Gable, S. L., \& Reis, H. T. (2010). Good news! Capitalizing on positive events in an interpersonal context. In M. P. Zanna (Ed.), Advances in Experimental Social Psychology (pp. 195-257). San Diego, CA: Elsevier Academic Press.

Gable, S. L., Reis, H. T., Impett, E. A., \& Asher, E. R. (2004). What do you do when things go right? The intrapersonal and interpersonal benefits of sharing positive events. Journal of Personality and Social Psychology, 87, 228-245. https://doi.org/10.1037/0022-3514.87.2.228

Gallagher, M. W., Lopez, S. J., \& Preacher, K. J. (2009). The hierarchical structure of Well-being. Journal of Personality, 77, 1025-1050. https://doi.org/10.1111/j.1467-6494.2009.00573.x

Goodwin, R. (1999). Personal relationships across cultures. London: Routledge.

Gore, J. S., Cross, S. E., \& Morris, M. L. (2006). Let's be friends: Relational self-construal and the development of intimacy. Personal Relationships, 13, 83-102. https://doi. org/10.1111/j.1475-6811.2006.00106.x

Grewen, K. M., Anderson, B. J., Girdler, S. S., \& Light, K. C. (2003). Warm partner contact is related to lower cardiovascular reactivity. Behavioral Medicine, 29, 123-130. https://doi. org/10.1080/08964280309596065

Gunnar, M. R., Brodersen, L., Krueger, K., \& Rigatuso, J. (1996). Dampening of adrenocortical responses during infancy: Normative changes and individual differences. Child Development, 67, 877-889. https://doi.org/10.1111/j.1467-8624.1996.tb01770.x

Hane, A. A., \& Fox, N. A. (2006). Ordinary variations in maternal caregiving influence human infants' stress reactivity. Psychological Science, 17, 550-556. https://doi. org/10.1111/j.1467-9280.2006.01742.x

Harlow, H. F. (1958). The nature of love. American Psychologist, 13, 673-685.

Hofer, M. A. (1984). Relationships as regulators: A psychobiologic perspective on bereavement. Psychosomatic Medicine, 46, 183-197.

Holt-Lunstad, J., Smith, T. B., \& Layton, J. B. (2010). Social relationships and mortality risk: A meta-analytic review. PLoS Medicine, 7, 1-20. https://doi.org/10.1371/journal.pmed.1000316

Imamoğlu, E. O., Küller, R., Imamoğlu, V., \& Küller, M. (1993). Social psychological worlds of Swedes and Turks in and around retirement. Journal of Cross-Cultural Psychology, 24, 26-41. https://doi.org/10.1177/0022022193241002

Imamoğlu, E. O., \& Selcuk, E. (2018). Cultural and self-related considerations in relationship well-being: With particular reference to marriage in Turkey. In C. C. Weisfeld, G. E. Weisfeld, \& L. M. Dillon (Eds.), Psychology of marriage: An evolutionary and cross-cultural view (pp. 89-106). New York: Lexington.

Kahneman, D., Krueger, A. B., Schkade, D. A., Schwarz, N., \& Stone, A. A. (2004). Survey method for characterizing daily life experience: The day reconstruction method. Science, 306, 1776-1780. https://doi.org/10.1126/science.1103572

Khan, C. M., Iida, M., Stephens, M. A. P., Fekete, E. M., Druley, J. A., \& Greene, K. A. (2009). Spousal support following knee surgery: Roles of self-efficacy and perceived emotional responsiveness. Rehabilitation Psychology, 54, 28-32. https://doi.org/10.1037/a0014753

Killingsworth, M. A., \& Gilbert, D. T. (2010). A wandering mind is an unhappy mind. Science, 330, 932. https://doi.org/10.1126/science.1192439

Kumashiro, M., Rusbult, C. E., Wolf, S. T., \& Estrada, M. J. (2006). The Michelangelo phenomenon: Partner affirmation and self movement toward one's ideal. In K. D. Vohs \& E. J. Finkel (Eds.), Self and relationships: Connecting intrapersonal and interpersonal processes (pp. 317 341). New York: Guildford Press.

Lakey, B. (2013). Perceived social support and happiness: The role of personality and relational processes. In S. A. David, I. Boniwell, \& A. C. Ayers (Eds.), The Oxford handbook of happiness (pp. 847-859). Oxford, UK: Oxford University Press.

Langston, C. A. (1994). Capitalizing on and coping with daily-life events: Expressivity responses to positive events. Journal of Personality and Social Psychology, 67, 1112-1125. https://doi. org/10.1037/0022-3514.67.6.1112

Li, T., \& Cheng, S.-T. (2015). Family, friends, and subjective well-being: A comparison between the West and Asia. In M. Demir (Ed.), Friendship and happiness: Across the life-span and cultures (pp. 235-251). Dordrecht, Netherlands: Springer. 
Lindfors, P., Berntsson, B., \& Lundberg, U. (2006). Factor structure of Ryff's psychological Wellbeing scales in Swedish female and male white-collar workers. Personality and Individual Differences, 40, 1213-1222. https://doi.org/10.1016/j.paid.2005.10.016

Lu, L. (2001). Understanding happiness: A look into the Chinese folk psychology. Journal of Happiness Studies, 2, 407-432. https://doi.org/10.1023/A:1013944228205

Lucas, R. E. (2007). Adaptation and the set-point model of subjective Well-being: Does happiness change after major life events? Current Directions in Psychological Science, 16, 75-79. https:// doi.org/10.1111/j.1467-8721.2007.00479.x

Maisel, N. C., Gable, S. L., \& Strachman, A. (2008). Responsive behaviors in good times and in bad. Personal Relationships, 15, 317-338. https://doi.org/10.1111/j.1475-6811.2008.00201.x

Mallers, M. H., Charles, S. T., Neupert, S. D., \& Almeida, D. M. (2010). Perceptions of childhood relationships with mother and father: Daily emotional and stressor experiences in adulthood. Developmental Psychology, 46, 1651-1661. https://doi.org/10.1037/a0021020

Markiewicz, D., Lawford, H., Doyle, A. B., \& Haggart, N. (2006). Developmental differences in adolescents' and young adults' use of mothers, fathers, best friends, and romantic partners to fulfill attachment needs. Journal of Youth and Adolescence, 35, 127-140. https://doi. org/10.1007/s10964-005-9014-5

Mikulincer, M., \& Shaver, P. (2007). Attachment patterns in adulthood: Structure, dynamics, and change. New York: Guilford Press.

Monfort, S. S., Kaczmarek, L. D., Kashdan, T. B., Drazkowski, D., Kosakowski, M., Guzik, P., \& Gracanin, A. (2014). Capitalizing on the success of romantic partners: A laboratory investigation on subjective, facial, and physiological emotional processing. Personality and Individual Differences, 68, 149-153. https://doi.org/10.1016/j.paid.2014.04.028

Otto, A. K., Laurenceau, J. P., Siegel, S. D., \& Belcher, A. J. (2015). Capitalizing on everyday positive events uniquely predicts daily intimacy and Well-being in couples coping with breast cancer. Journal of Family Psychology, 29, 69-79. https://doi.org/10.1037/fam0000042

Pavot, W., \& Diener, E. (2013). Happiness experienced: The science of subjective Well-being. In S. A. David, I. Boniwell, \& A. C. Ayers (Eds.), The Oxford handbook of happiness (pp. 134151). Oxford, UK: Oxford University Press.

Pflug, J. (2009). Folk theories of happiness: A cross-cultural comparison of conceptions of happiness in Germany and South Africa. Journal of Social Indicators Research, 92, 551-563. https://doi.org/10.1007/s11205-008-9306-8

Proulx, C. M., Helms, H. M., \& Buehler, C. (2007). Marital quality and personal Wellbeing: A meta-analysis. Journal of Marriage and Family, 69, 576-593. https://doi. org/10.1111/j.1741-3737.2007.00393.x

Ramsey, M. A., \& Gentzler, A. L. (2015). An upward spiral: Bidirectional associations between positive affect and positive aspects of close relationships across the life span. Developmental Review, 36, 58-104. https://doi.org/10.1016/j.dr.2015.01.003

Reis, H. T. (2007). Steps toward the ripening of relationship science. Personal Relationships, 14, 1-23 doi: 1350-4126/07.

Reis, H. T. (2012a). Perceived partner responsiveness as an organizing theme for the study of relationships and well-being. In L. Campbell \& T. Loving (Eds.), Interdisciplinary research on close relationships: The case for integration (pp. 27-52). Washington, DC: American Psychological Association.

Reis, H. T. (2012b). A brief history of relationship research in social psychology. In A. W. Kruglanski \& W. Stroebe (Eds.), Handbook of the history of social psychology (pp. 363-382). New York: Psychology Press.

Reis, H. T. (2013). Relationship Well-being: The central role of perceived partner responsiveness. In C. Hazan \& M. I. Campa (Eds.), Human bonding: The science of affectional ties (pp. 283307). New York: Guilford Press.

Reis, H. T., Clark, M. S., \& Holmes, J. G. (2004). Perceived partner responsiveness as an organizing construct in the study of intimacy and closeness. In D. Mashek \& A. Aron (Eds.), Handbook of closeness and intimacy (pp. 201-255). Mahwah, NJ: Lawrence Erlbaum Associates. 
Reis, H. T., \& Gable, S. L. (2015). Responsiveness. Current Opinion in Psychology, 1, 67-71. https://doi.org/10.1016/j.copsyc.2015.01.001

Reis, H. T., \& Shaver, P. (1988). Intimacy as an interpersonal process. In S. Duck (Ed.), Handbook of personal relationships (pp. 367-389). Chichester, England: Wiley.

Robles, T. F., Slatcher, R. B., Trombeloo, J. M., \& Mcginn, M. M. (2014). Marital quality and health: A meta-analytic review. Psychological Bulletin, 140, 140-187. https://doi.org/10.1037/ a0031859

Ryff, C. D. (2013). Psychological Well-being revisited: Advances in the science and practice of eudaimonia. Psychotherapy and Psychosomatics, 83, 10-28.https://doi.org/10.1159/000353263

Salter, P. S., \& Adams, G. (2012). Mother or wife? An African dilemma tale and the psychological dynamics of sociocultural change. Social Psychology, 43, 232-242. https://doi. org/10.1027/1864-9335/a000124

Sapphire-Bentler, S., \& Taylor, S. (2013). Close relationships and happiness. In S. A. David, I. Boniwell, \& A. C. Ayers (Eds.), The Oxford handbook of happiness (pp. 821-833). Oxford, UK: Oxford University Press.

Selcuk, E., Gunaydin, G., Ong, A. D., \& Almeida, D. M. (2016). Does partner responsiveness predict hedonic and eudaimonic well-being? A 10-year longitudinal study. Journal of Marriage and Family, 78, 311-325. https://doi.org/10.1111/jomf.12272

Selcuk, E., Gunaydin, G., Sumer, N., Harma, M., Salman, S., Hazan, C., et al. (2010). Self-reported romantic attachment style predicts everyday maternal caregiving behavior at home. Journal of Research in Personality, 44, 544-549. https://doi.org/10.1016/j.jrp.2010.05.007

Selcuk, E., \& Ong, A. D. (2013). Perceived partner responsiveness moderates the association between received emotional support and all-cause mortality. Health Psychology, 32, 231-235. https://doi.org/10.1037/a0028276

Selcuk, E., Stanton, S. C., Slatcher, R. B., \& Ong, A. D. (2017). Perceived partner responsiveness predicts better sleep quality through lower anxiety. Social Psychological and Personality Science, 8, 83-92. https://doi.org/10.1177/1948550616662128

Selcuk, E., Zayas, V., Günaydın, G., Hazan, C., \& Kross, E. (2012). Mental representations of attachment figures facilitate recovery following upsetting autobiographical memory recall. Journal of Personality and Social Psychology, 103, 362-378. https://doi.org/10.1037/a0028125

Selcuk, E., Zayas, V., \& Hazan, C. (2010). Beyond satisfaction: The role of attachment in marital functioning. Journal of Family Theory and Review, 2, 258-279. https://doi.org/10.111 $1 / \mathrm{j} .1756-2589.2010 .00061$

Shulman, S., \& Connolly, J. (2013). The challenge of romantic relationships in emerging adulthood: Reconceptualization of the field. Emerging Adulthood, 1, 27-39. https://doi. org/10.1177/2167696812467330

Simpson, J. A., Collins, W. A., Tran, S., \& Haydon, K. C. (2007). Attachment and the experience and expression of emotions in romantic relationships: A developmental perspective. Journal of Personality and Social Psychology, 92, 355-367. https://doi.org/10.1037/0022-3514.92.2.355

Simpson, J. A., Rholes, W. S., \& Nelligan, J. (1992). Support-seeking and support-giving within couples in an anxiety provoking situation: The role of attachment styles. Journal of Personality and Social Psychology, 62, 434-446. https://doi.org/10.1037/0022-3514.62.3.434

Slatcher, R., \& Selcuk, E. (2017). A social psychological perspective on the links between close relationships and health. Current Directions in Psychological Science, 26, 16-21. https://doi. org/10.1177/0963721416667444

Slatcher, R., Selcuk, E., \& Ong, A. D. (2015). Perceived partner responsiveness predicts diurnal cortisol profiles 10 years later. Psychological Science, 26, 972-982. https://doi. org/10.1177/0956797615575022

Sroufe, L. A., \& Waters, E. (1977). Attachment as an organizational construct. Child Development, 48, 1184-1199. https://doi.org/10.2307/1128475

Stanton, S. C. E., Zilioli, S., Briskin, J. L., Imami, L., Tobin, E. T., Wildman, D. E., et al. (2017). Mothers' attachment is linked to their children's anti-inflammatory gene expression via maternal warmth. Social Psychological and Personality Science, 8, 796-805. https://doi. org/10.1177/1948550616687125 
Tasfiliz, D., Sagel, E., \& Selcuk, E. (2016). Algılanan partner duyarlılığında yaş farklılıkları ve iyi oluş hali ile ilişkisi [Age differences in partner responsiveness and links to psychological wellbeing in Turkey]. Manuscript in preparation.

Tasfiliz, D., Selcuk, E., Gunaydin, G., Slatcher, R. B., Corriero, E., \& Ong, A. D. (2018). Patterns of perceived partner responsiveness and Wellbeing in Japan and the United States. Journal of Family Psychology, 32, 355-365. https://doi.org/10.1037/fam0000378

Taylor, S. E. (2002). The tending instinct: How nurturing is essential to who we are and how we live. New York: Holt.

Uvnas-Moberg, K. (1998). Oxytocin may mediate the benefits of positive social interaction and emotions. Psychoneuroendocrinology, 23, 819-835. https://doi.org/10.1016/ S0306-4530(98)00056-0

Van Dierendonck, D. (2004). The construct validity of Ryff's scales of psychological Well-being and its extension with spiritual Well-being. Personality and Individual Differences, 36, 629643. https://doi.org/10.1016/S0191-8869(03)00122-3

Vormbrock, J. K. (1993). Attachment theory as applied to wartime and job-related marital separation. Psychological Bulletin, 114, 122-144. https://doi.org/10.1037/0033-2909.114.1.122

Wu, T., Cross, S. E., Wu, C., Cho, W., \& Tey, S. (2016). Choosing your mother or your spouse: Close relationship dilemmas in Taiwan and the United States. Journal of Cross-Cultural Psychology, 47, 558-580. https://doi.org/10.1177/0022022115625837

Zayas, V., Günaydin, G., \& Shoda, Y. (2015). From an unknown other to an attachment figure: How do mental representations change with attachment formation? In V. Zayas \& C. Hazan (Eds.), Bases of adult attachment: Linking brain, mind and behavior (pp. 157-183). Springer: New York.

Zayas, V., Mischel, W., Shoda, Y., \& Aber, J. L. (2011). Roots of adult attachment: Maternal caregiving at 18 months predicts adult attachment to peers and partners. Social Psychological and Personality Science, 2, 289-297. https://doi.org/10.1177/1948550610389822

Zeifman, D., \& Hazan, C. (1997). Attachment: The bond in pair-bonds. In J. A. Simpson \& D. T. Kenrick (Eds.), Evolutionary social psychology (pp. 237-263). Mahwah, NJ: Erlbaum.

Zeifman, D., \& Hazan, C. (2008). Pair bonds as attachments: Reevaluating the evidence. In J. Cassidy \& P. Shaver (Eds.), Handbook of attachment: Theory, research and clinical implications (pp. 436-455). New York: Guilford Press. 